\title{
AS METODOLOGIAS DE ENSINO DE CIÊNCIAS: CONTRIBUIÇÕES DA EXPERIMENTAÇÃO E DA HISTÓRIA E FILOSOFIA DA CIÊNCIA
}

\author{
M. C. E. S. Ataide e B. V. C. Silva
}

Universidade Federal do Piauí (UFPI). Grupo de Ensino e Pesquisa em Ensino de Ciências marciaeloi@ufpi.edu.br - boniek@ufpi.edu.br

\section{RESUMO}

Neste artigo realizamos um resgate sobre a evolução do ensino de ciências e suas metodologias com o intuito de discutirmos de forma específica a inserção da história e filosofia da ciência e das atividades experimentais como ferramentas didáticas. Propomos ainda a utilização das ferramentas descritas acima como auxílio na preparação de unidades didáticas, projetos de ensino e no uso de atividades experimentais, dentre outras nas licenciaturas na área de ciências.

PALAVRAS-CHAVE: Ensino de Ciências, Atividades Experimentais, História e Filosofia da Ciência.

\section{THE METHODS OF SCIENCE EDUCATION: CONTRIBUTIONS OF EXPERIMENTATION AND HISTORY AND PHILOSOPHY OF SCIENCE}

\begin{abstract}
In this article we do a rescue on the evolution of science education and teaching methods with the intention to discuss specifically the inclusion of history and philosophy of science and experimental activities as teaching tools. We also propose the use of the tools
\end{abstract}

described above as an aid in the preparation of teaching units, teaching projects and in the use of experimental activities, among other graduates in the sciences.

KEY-WORDS: Science Education, Experimental Activities, History and Philosophy of Science. 


\section{AS METODOLOGIAS DE ENSINO DE CIÊNCIAS: CONTRIBUIÇÕES DA EXPERIMENTAÇÃO E DA HISTÓRIA E FILOSOFIA DA CIÊNCIA}

\section{INTRODUÇÃO}

Nos dias atuais, muito devido à consolidação da didática das ciências como um campo coeso e robusto de pesquisa, as discussões relacionadas às práticas do docente em sala de aula $^{1}$ têm alcançado um espaço significativo na literatura especializada (DELIZOICOV; ANGOTTI; PERNAMBUCO, 2002; CARVALHO; GIL-PÉREZ, 2006).

Entretanto, como é mostrado por Krasilchik (1987), desde as décadas de 60 e 70 do século passado, o movimento de mudança curricular no ensino de ciências já era objeto de discussão das mais variadas academias especializadas da área. Citemos, por exemplo: as discussões curriculares acontecidas na Inglaterra e Estados Unidos, nesta mesma época, decorrentes da corrida armamentista, influenciada pela guerra fria.

Para todas estas discussões percebíamos algo em comum: a eminente decadência do ensino de ciências, apontada pelo desinteresse dos jovens pelas carreiras científicas. Esses embates culminaram em diversos projetos de ensino, por exemplo: CHEMS (Chemical Education Material Study), o CBA (Chemical Bond Aproach Project), o Nuffield de Química (década de 1960), American Association for the Advancement of Science nos E.U.A. e The Liberal Art of Science, na Inglaterra (KRASILCHILK, 1987).

Neste período, a década de 70 do século passado, o Brasil iniciava o processo de democratização do ensino, e, de forma específica, uma maior abertura ao ensino para as classes de menor poder aquisitivo (KRASILCHIK, 1987). Nestas situações, como é discutido por Delizoicov, Angotti e Pernambuco (2002), as escolas recebiam uma nova clientela: as classes menos favorecidas economicamente.

Diante disto, a escola elitista, centrada nas classes mais abastadas, deveria mudar o seu perfil de ensino-aprendizagem. A escola deveria passar por um momento de mudança paradigmática, em uma linguagem kuhniana (KUHN, 1987).

Muitas dessas mudanças, como a abertura da população com menor poder econômico ao ensino de ciências, podem ser entendidas, pois o mundo e o Brasil, em especial, viviam uma revolução tecnológica, onde tanto as empresas precisavam de mão-de-obra especializada para ocuparem seu campo de trabalho como o comércio necessitava de uma clientela com um grau mínimo sobre ciências para entenderem e comprarem os novos produtos que surgiam nas lojas.

\footnotetext{
${ }^{1}$ Consideramos a sala de aula como o espaço físico da escola e espaços não formais de ensino, por exemplo: museus, parques da ciência, sites da internet.
} 
Como podemos verificar, a sociedade das décadas de 60 e 70 do século passado passou por uma verdadeira mudança e era papel da escola tentar acompanhá-las.

Entretanto, a escola, neste período, vivia um momento fortemente impregnado por uma tendência tecnicista, amparada em uma filosofia de ensino tradicionalista, na qual o professor era o centro do processo de ensino-aprendizagem e o aluno um ser passivo, onde o seu papel, nessa história, era de servir de receptáculo das informações do mestre.

Essa visão de ensino-aprendizagem trazia no seu cerne uma variedade de posturas epistemológicas, por exemplo: o aluno sendo uma tábula rasa, ou seja, não possuidor de ideias anteriores ao chegar à escola.

A década de 80 , em especial, foi marcada pela contestação deste modelo de ensinoaprendizagem, que mostrava, em alguns casos, não dá conta de instrumentalizar os alunos frente às teorias científicas.

Nesta direção, o modelo construtivista, que surgiu como antagônico ao modelo tradicionalista e de natureza behaviorista, seria empregado na inovação e construção de várias metodologias de ensino.

Contudo, como destaca Carvalho e Gil-Pérez (2006), muitas destas inovações, sejam elas curriculares ou metodológicas, não alcançavam as salas de aulas e os professores que lá atuavam. Isto dificultou e ainda dificultam, nos dias atuais, as perspectivas de uma renovação no ensino.

Infelizmente, a ideia da formação inicial como um momento de encerramento de uma etapa de formação do docente, seja ele de ciências ou não, ainda é muito enraizada no imaginário de muitos dos futuros professores.

De forma genérica, não viríamos grandes problemas nessa forma de pensar, desde que a formação inicial suprisse todas as necessidades do professorando. Mas, como aponta Carvalho e Gil-Pérez (2006), a formação inicial, por si só, não consegue abraçar todas as competências e habilidades de forma satisfatória que o licenciado necessitaria. Citemos algumas: o trabalho como as novas tecnologias, uma discussão sobre o uso do laboratório do ensino de ciências, a utilização da história e da filosofia da ciência no ensino, dentre outras.

Entretanto, existem algumas exceções e como comentam Delizoicov, Angotti e Pernambuco (2002), elas deverão ser trabalhadas na perspectiva da formação do professor de ciências, dando-lhes melhores subsídios.

Para Carvalho e Gil-Pérez (2006), uma das possibilidades de melhorar a formação dos professores é o trabalho coletivo. Dessa forma, para os autores, seria possível analisar e 
criticar algumas visões simplistas do ensino de ciências, por exemplo: para ser um bom professor é necessário apenas o domínio do conteúdo.

Ainda, segundo os autores citados acima, ao trabalhar em grupos as discussões dos professores se aproximam mais do que é debatido na didática das ciências. Dessa forma, os trabalhos coletivos fornecem aos professores melhores subsídios no que diz respeito ao saber e ao saber fazer em ciências.

Uma das possibilidades adotada por Carvalho e Gil-Pérez (2006) nos grupos de discussão é a filmagem das aulas dos participantes. Dessa forma, espera-se que, em um momento posterior, essas filmagens possam favorecer um momento de re (construção) tanto do saber pedagógico, das metodologias usadas para cada conteúdo, como de visões equivocadas sobre a natureza da ciência. Assim, os autores esperam uma tomada de consciência dos professorandos, passando, assim, por um momento de metacognização ${ }^{2}$ própria. É vivenciando as práticas e as novas metodologias no seu dia-a-dia que o futuro professor poderá passar por uma avaliação mais elaborada do desenvolvimento de sua prática, evitando assim posturas acríticas comumente repetidas em sala de aula.

As últimas discussões desenvolvidas pela Didática das Ciências relacionadas aos professores em exercício dão suporte para a idealização de novas práticas e metodologias que vão contra o currículo escolar enciclopédico e ao mesmo tempo reduzido, pois deixam de fora, por exemplo, as discussões sobre ciência, tecnologia e sociedade além da experimentação como atividade investigativa.

Atualmente, decorrente das discussões desenvolvidas em torno da área da Didática das Ciências, existem várias vertentes metodológicas das pesquisas, citemos algumas, por exemplo: atividades experimentais e o uso da história e da filosofia da ciência no ensino de ciências, o ensino por redescoberta, o modelo de mudança conceitual, o ensino por projetos, o ensino baseado no perfil conceitual, dentre outras. Hoje elas, cada uma de sua forma, tentam lograr melhorias no Ensino de Ciências.

Neste trabalho apresentaremos as duas primeiras vertentes citadas acima, que servem como subsídios para a elaboração de unidades didáticas, mostrando inclusive as possíveis contribuições na melhoria do processo de ensino-aprendizagem de biologia, física, ciências e química.

\footnotetext{
${ }^{2}$ Para maiores detalhes, consulte Nuñez e Ramalho (2004).
} 


\section{ATIVIDADES EXPERIMENTAIS NO ENSINO DE CIÊNCIAS: POSSIBILIDADES DE USO EM SALA DE} AULA

O uso de atividades experimentais no currículo tem sido foco de grandes discussões entre profissionais do ensino de ciências, dentre eles: Giordan (1999), Dourado (2001), Silva e Neves (2006), Caamaño (2007), Ataide (2010) e outros.

Os documentos oficiais, dentre eles: os Parâmetros Curriculares Nacionais para o ensino médio (PCN) e as Orientações Curriculares para o Ensino Médio (OCEM), destacam o uso de experimentos como estratégia de abordar diversos temas por fazerem parte da vida, da escola e do cotidiano de todos.

As atividades experimentais não devem ser exclusivamente realizadas em um laboratório com roteiros seguidos nos mínimos detalhes e sim, partir de um problema ou questão a ser respondida (BRASIL, 2002, p.71). As OCEM sinalizam que a experimentação não garante a produção de conhecimentos significativamente, mas é uma importante ferramenta para construção do mesmo.

De acordo com Rosito (2003), o papel da experimentação possibilita aos estudantes a aproximação com o trabalho científico e melhora a relação entre professores e alunos.

Enfatizamos ainda que a realização de experimentos na escola não atende as mesmas funções que as realizadas pelos cientistas, porque possuem objetivos diferentes; como forma de auxiliar nas orientações dos experimentos, Izquierdo et al (1999) defendem o uso de perguntas como: ‘O que está sendo feito?'e 'O que ocorreu?'.

No momento da realização do seu planejamento, o professor deve pensar nas possíveis respostas que explicam os fenômenos envolvidos. Para as atividades experimentais no ensino de ciências, a interpretação de dados ou fenômenos, elaboração de hipóteses, manuseio e instrumentação de equipamentos, resolução de problemas, análise de dados e a argumentação favorecem a relação entre teoria e prática.

Martínez e Parrilla (1994) defendem que a aprendizagem deve contemplar três componentes, são eles: conteúdos conceituais, procedimentos da resolução de problemas e aquisição dos objetivos gerais de aprendizagem na realização de experimentos.

Tomando como referência a aprendizagem na realização de experimentos, os autores, acima citados, destacam a contribuição para a modificação das concepções prévias dos alunos: o desenvolvimento de procedimentos e habilidades específicas da atividade experimental, o reforço da compreensão dos conteúdos conceituais, o estímulo atitudes positivas sobre atividades científicas e o contato com a tecnologia em situações parecidas com as de um processo produtivo. 
O professor de ciências ao trabalhar com estas atividades poderá, por exemplo, "estabelecer relações com implicações ambientais e abordar o tema descarte de rejeitos químicos" (ATAIDE, 2010 p. 20).

Nesta perspectiva Neves e Silva (2006) alertam que para a disciplina de química, as atividades experimentais utilizam procedimentos, habilidades e técnicas próprias, por isso, necessitam de cuidados com a segurança e manuseio dos reagentes, gerenciamento dos resíduos produzidos nas atividades desenvolvidas nos laboratórios didáticos ou em outro espaço específico.

Com relação ao espaço para realizar as atividades experimentais, os PCN consideram os "experimentos simples, que podem ser realizados em casa, no pátio da escola ou na sala de aula com materiais do dia-a-dia podem levar a descobertas importantes" (BRASIL, 2002, p.71). As atividades executadas na escola devem contribuir na elaboração de explicações teóricas feita pelos próprios estudantes, estes poderão discutir os resultados obtidos, construir tabelas e gráficos.

De acordo com Silva e Neves (2006), apesar de muitos professores acreditarem que as atividades experimentais facilitam a aprendizagem dos alunos, estas são pouco realizadas. Os autores explicam as possíveis justificativas para este fator quando falam da polêmica do uso de experimentos nas escolas. Para Ataide (2010), são três os aspectos:

"de natureza filosófica (a realização de atividades experimentais de forma livre ou sem orientação); natureza cognitiva (a adequação ou não das atividades experimentais às habilidades dos estudantes na escola) e de natureza pedagógica (o espaço físico como os laboratórios, condições dos materiais como vidrarias, reagentes $e$ preparação de professores)" (ATAIDE, 2010, p. 23)

O aspecto de natureza pedagógica é o mais destacado por professores em exercício. Alguns docentes relatam a falta de espaço físico próprio para a realização das atividades, a ausência de reagentes e materiais necessários, e uma deficitária preparação para este tipo de atividade como sendo os principais problemas para o aspecto citado (SILVA e NEVES, 2006, p. 7).

De forma específica, a falta de preparação do professor aponta para a deficiência nos cursos de formação inicial. Alguns professores argumentam que não fazem atividades experimentais por não dispor de tempo acarretando em aulas conteudistas baseadas na relação teoria-exercício-teoria (ATAIDE, 2010).

No tópico seguinte discutiremos o uso da história e filosofia da ciência (HFC) como ferramenta didática. 


\section{A HISTÓRIA E A FILOSOFIA DA CIÊNCIA NA SALA DE AULA: PROBLEMAS E POSSIBILIDADES}

A contestação do ensino de ciências, nos dias atuais, nas escolas de ensino fundamental ou médio é algo que já vem sendo discutido e relatado nos eventos e congressos da área (SILVA, 2010a). Este fato, em alguns casos, pode ser explicado pelas metodologias de ensino que são utilizadas nas salas de aula, por exemplo: a relação teoria-exercício-teoria, a qual, em algumas situações, somente repassa a preocupação em afixar fórmulas, fatos e teorias, chegando a um estado de "decorar" uma equação científica.

Segundo os PCN, o ensino de física, por exemplo, deve ser pautado em eixos que não são, em alguns casos, abordados nas salas de aula, a saber: compreender o conhecimento científico e o tecnológico como resultados de uma construção humana, inseridos em um processo histórico e social (BRASIL, 2002).

Nesse sentido pode-se indagar: como podemos formar nossos alunos nesse tipo de competência destacada nos PCN?

Uma das várias possibilidades discutidas na literatura especializada (veja, por exemplo: MATTHEWS, 1995; EL-HANI, 2006; SILVA, 2010a) é o uso da HFC no ensino de ciências. A mesma literatura aborda que a visão de ciência dos alunos de todos os níveis se mostra equivocada, quando comparada à concepção de ciência encarada pela literatura como adequada ${ }^{3}$.

Esse fato, as distorções sobre a noção de ciência dos alunos do ensino médio, é apontado por Silva (2010b), que, em seu trabalho, mapeou as concepções de ciências apresentadas por um grupo de alunos do ensino médio.

Dessa forma chegamos à elaboração de outra questão: como melhorar a noção de ciência apresentada pelos alunos, sejam eles do ensino fundamental, médio ou superior?

Novamente podemos recorrer a HFC, onde a sua inserção pode contribuir para a melhoria de aspectos da natureza da ciência, por exemplo: a percepção da ciência como atividade humana, a falibilidade dos cientistas e o mito do gênio da ciência.

Especialmente e devido à própria natureza da HFC, a qual apresenta um potencial pedagógico favorável ao docente que tenha por ambição lograr melhorias nas competências discutidas acima, que possibilita a interação com outras disciplinas como as de história, filosofia, artes, religião, possibilitando inclusive a (re)criação de várias práticas de ensino, por exemplo: textos históricos, peças teatrais, debates, júri simulado, unidades didáticas, dentre outras.

\footnotetext{
${ }^{3}$ Para discussões mais aprofundadas sobre a natureza da ciência e o que a literatura especializada considera como visão de ciência dita como adequada, consulte: El-Hani (2006) e Silva (2010b).
} 
Dessa forma, por exemplo, uma unidade didática que apresente, no seu cerne, a HFC pode funcionar como uma boa saída para a constante desmotivação encontrada nas aulas de ciências. No Brasil, desde a criação dos PCN, vários programas relacionados à educação científica tentam elaborar saídas para o pessimismo que aflora nas aulas de ciências. Nesse sentido, estratégias didáticas que envolvam a HFC podem ser mecanismos relevantes para apresentar aos alunos uma ciência mais viva e dinâmica.

Portanto, o uso da HFC no ensino de ciências pode:

- Proporcionar o estudo mais adequado de equações relacionadas a conceitos e teorias que, em algumas ocasiões, vêm se mostrar sem significação aos estudantes;

- Servir como uma ferramenta no trabalho das concepções prévias mostradas pelos alunos;

- Desmistificar o método científico, possibilitando ao aluno um estudo mais detalhado do trabalho dos cientistas, mostrando que nem sempre é preciso, para a aceitação ou não de uma teoria, finalizar o processo por meio de um experimento com caráter de "verificação" ou mostrando, ainda, que diferentes cientistas se valiam de metodologias diferentes para realizar as suas pesquisas, afastando-se, em muitos casos, dos conhecidos passos do famoso método empírico-indutivista;

- Proporcionar o estudo e elaboração de novas estratégias de ensino que possibilitem dar uma maior significação ao estudo de conceitos e teorias físicas;

- Mostrar tanto os acertos quanto os erros na ciência;

- Mostrar os problemas, dificuldades e dilemas que rodeiam o cientista na formulação de uma teoria;

- Contribuir para o entendimento da relação ciência, tecnologia e sociedade.

Devido à própria natureza da história da ciência, que requer a constante leitura de obras de cientistas, em muitos casos, nas unidades didáticas são elaborados textos históricos, os quais podem criar uma ponte entre ciência e literatura. Acreditamos que os textos históricos possam:

- Propiciar a leitura de textos científicos;

- Servir de ferramenta para a apresentação de situações-problemas de forma aberta;

- Favorecer o debate, a arguição e a argumentação escrita e oral.

Entretanto, é claro que o uso da HFC e a elaboração de textos históricos e unidades didáticas norteadas pela HFC não são tarefa triviais. Mas, acreditamos que a sua inserção no ensino de ciências pode se tornar um elemento motivador para elaboração de novas metodologias de ensino. 
Abaixo, nas considerações finais, abordaremos a nossa experiência de introdução dessas metodologias nos cursos de licenciatura em física, química, ciências e biologia da Universidade Federal do Piauí (UFPI).

\section{CONSIDERAÇÕES FINAIS}

Entendemos que mudanças didáticas não sejam tarefas fáceis e em alguns casos não são encaradas com bons olhos, como podemos observar na própria história do ensino de ciências discutido neste trabalho. Especificamente sobre as metodologias de ensino de ciências utilizadas na área, pode-se observar que embora elas sejam repensadas, a sua forma de utilização em sala de aula ainda é discreta, onde se observa um abismo entre as pesquisas em ensino e o que realmente é feito em sala de aula.

Nesse ponto, os autores deste artigo, no trabalho com os alunos das licenciaturas de física, química, ciências e biologia da UFPI, inserem tais discussões no sentido de elaborar materiais e projetos de ensino que possam ser desenvolvidos e aplicados pelos alunos das disciplinas de estágio supervisionado e práticas de ensino nas escolas campo de estágio.

No caso do uso da HFC, os alunos participantes discutem, elaboram e aplicam no seu campo de estágio tanto unidades didáticas como peças teatrais, debates, júri simulado fundamentados pela história da ciência, onde se discute inclusive aspectos da natureza do conhecimento científico. Já a inserção da experimentação no ensino de ciências pretende-se estimular o desenvolvimento de materiais didáticos, como produção de vídeos com experimentos, e projetos de ensino para aplicação na sua escola campo de estágio de acordo com a necessidade.

Os resultados desta empreitada serão objetos de discussões para futuros trabalhos.

\section{REFERÊNCIAS BIBLIOGRÁFICAS}

1. ATAIDE, M. C. E. S. Experimentos que geram rejeitos químicos com metais pesados em escolas da educação básica. 2010. Programa de Pós-Graduação em Ensino de Ciências Naturais e Matemática do Centro de Ciências Exatas e da Terra da Universidade Federal do Rio Grande do Norte, UFRN, Universidade Federal do Rio Grande do Norte, Natal.

2. BRASIL. MINISTÉRIO DA EDUCAÇÃO E CULTURA. Parâmetros Curriculares Nacionais Ensino Médio. Brasília: 2002.

3. CAAMAÑO, A. Los trabajos prácticos en ciencias. In: ALEIXANDRE (Org). Enseñar Ciencias. Madrid: Editora Graó, 2007, p. 95-118. 
4. CARVALHO, A. M. P.; GIL-PÉREZ, D. Formação de professores de Ciências. Tradução de Sandra Valenzuela. São Paulo: Cortez, 2006.

5. DELIZOICOV, D.; ANGOTTI, J. A.; PERNAMBUCO, M. M. Ensino de Ciências: Fundamentos e métodos. São Paulo: Cortez, 2002.

6. DOURADO, L. Trabalho Prático, trabalho laboratorial, trabalho de campo e trabalho experimental no ensino de ciências: contributo para uma clarificação de termos. In: Ensino experimental das ciências. Lisboa, 2001, p. 13-18.

7. EL-HANI, C. N. Notas sobre o ensino de história e filosofia da ciência na educação científica de nível superior. In: SILVA, C. C. Estudo de História e Filosofia das Ciências: subsídios para aplicação no ensino. São Paulo: Livraria da Física, p. 3-21, 2006.

8. GIORDAN, M. O papel da experimentação no ensino de Ciências. Química nova na Escola, n.10, 1999, p. 43-49.

9. IZQUIERDO, M.; SANMARTÍ, N.; ESPINET, M. Fundamentación y diseño de las prácticas escolares de ciencias experimentales. Enseñanza de las Ciencias, v.17, n.1. 1999, p. 4559.

10. KUHN, T. S. A Estrutura das Revoluções Científicas. Tradução: Boeira, B. V; Boeira, N. São Paulo: Editora Perspectiva, 1987.

11. KRASILCHIK, M. O professor e o currículo de ciências. Temas Básicos de educação e ensino. Ed. EPU. São Paulo, 1987.

12. MARTínEZ, H.C.; PARRILLA, P.J.L. La utilización Del ordenador em La realización de experiências de laboratório. Enseñanza de las Ciencias, v.12, n. 3, 1994. p. 393-399.

13. MATTHEWS, M. R. História, Filosofia e Ensino de Ciências: a tendência atual de reaproximação. Caderno Catarinense de Ensino de Física, Florianópolis, v. 12, n. 3, p.164-214, 1995.

14. NUÑEZ, I.B.(org); RAMALHO, B.L(org). Fundamentos do ensino-aprendizagem das ciências naturais e da matemática: o novo ensino médio. Porto Alegre: Sulina, 2004.

15. ROSITO, B. A. O ensino de ciências e a experimentação. In: MORAES, R. e or. Construtivismo e ensino de ciências reflexões epistemológicas e metodológicas. 2 ed. Porto Alegre: EDIPUCRS. 2003, p. 195-208.

16. SILVA, B. V. C. Controvérsias sobre a natureza da luz: uma aplicação didática. Dissertação de Mestrado. 2010a. Programa de Pós-Graduação em Ensino de Ciências 
Naturais e Matemática do Centro de Ciências Exatas e da Terra da Universidade Federal do Rio Grande do Norte, UFRN, Universidade Federal do Rio Grande do Norte, Natal.

17. A natureza da ciência pelos alunos do ensino médio: um estudo exploratório. Latin American Journal of Physics Education., v. 4, p. 670-677, 2010b.

18. SILVA, M.G.L.; NEVES, L. S. Instrumentação para o ensino de química I. Natal: EDUFRN, 2006. 